\title{
Proposta de formação continuada em serviço para professores que ensinam matemática nos anos iniciais em escolas do campo: percepções de professores e perspectivas de formação
}

\author{
Lúcia Maria Batista Fonseca ${ }^{1}$ \\ Arthur Gonçalves Machado Júnior ${ }^{2}$
}

\section{RESUMO}

Este produto educacional é resultado da pesquisa qualitativa modalidade pesquisaação realizada com professores dos anos iniciais do Ensino Fundamental, em escolas do Campo no município de Marabá (PA). O produto emergiu em resposta a seguinte questão. Em que termos uma proposta de formação continuada, em serviço, pode possibilitar a orientação do trabalho didático-pedagógico do professor ao ensinar Matemática nos anos iniciais do Ensino Fundamental em escolas do Campo? Os instrumentos utilizados foram: questionário; entrevista; observação; gravação de vídeo das aulas de matemática e intervenção na ação didático-pedagógica do professor. Contou-se com as contribuições de: Alarcão; Fiorentini e Nacarato; Freire; Imbernón e Tardif. $\mathrm{Na}$ análise os professores atribuem as dificuldades ao ensinar matemática ao processo de formação por eles vivido e ausência dos coordenadores pedagógicos nas ações docentes. Segundo os professores, o aspecto de maior relevante foi essa experiência formativa ter acontecido em contexto de trabalho e proporcionar outro olhar sobre o contexto da sala de aula, orientando o ato de ensinar e aprender matemática.

Palavras-chave: Formação continuada de professor. Ensino de matemática.

\section{ABSTRACT}

This educational product is a result of qualitative research action research mode held with teachers of the early years of elementary school, in the field schools in the municipality of Marabá (PA). The product emerged in response to the following question. In that we have a proposal for continuing training, on the job, you can enable the didactic-pedagogic work orientation of the teacher to teach Mathematics in the early years of primary education in schools in the country? The instruments used were: questionnaire; interview; observation; video recording of the math classes and didacticpedagogical action intervention. Told with contributions from: Alarcão; Fiorentini and Nacarato; Freire; Imbernón and Tardif. In analyzing the teachers attributed the difficulties to teach mathematics to the process of formation for them lived and absence of pedagogical coordinators in teachers. According to the teachers, the greater was this

\footnotetext{
1 Mestre em Docência em Ensino de Ciências e Matemáticas (IEMCI/UFPA), professora formadora de professores dos anos iniciais e servidora efetiva da prefeitura municipal de Marabá-p=PA, Email: luciafonseca64@hotmail.com

2 Doutor em Ciências e Matemáticas (IEMCI/UFPA), professor da Universidade Federal do Pará, Email: agmi@ufpa.br
} 
formative experience happened on the work context and provide another look at the context of the classroom, guiding the Act of teaching and learning mathematics.

Keywords: Continuing education of teacher. Teaching of mathematics.

\section{INTRODUÇÃO}

Este produto educacional, em formato de E-book, se constitui em parte integrante da Dissertação de Mestrado Profissional do curso de PósGraduação em Docência em Educação em Ciências e Matemática, que se estruturou com o título um olhar sobre a formação de professores que ensinam matemática nos anos iniciais do Ensino Fundamental em escolas do Campo.

O trabalho caracteriza-se em uma intervenção no processo de formação continuada de professores dos anos iniciais, que iniciou com uma diagnose e finalizou com atividades de intervenção na prática docente, chegando à culminância de uma proposta de formação continuada em serviço. Essa proposta está destinada aos coordenadores pedagógicos das escolas do Campo e teve como finalidade contribuir com o processo de formação continuada em serviço dos professores dos anos iniciais.

A proposta de formação continuada em serviço não teve o propósito de alterar mudanças no modelo de formação que vem sendo desenvolvidas com professores do Campo nas últimas duas décadas, nem de disponibilizar receita pronta, mas, de apontar possibilidades de outros caminhos formativos que considere os saberes empregados pelos docentes no desenvolvimento da prática pedagógica e que, a partir dessa lógica, a formação continuada possa ser desenvolvida em contexto de trabalho.

O produto educacional, aqui apresentado, compreende o resultado das práticas de cinco professores dos anos iniciais que desenvolvem a docência em três escolas do Campo; bem como as mudanças proporcionadas pela prática reflexiva e pela troca de ideias entre pesquisador e pesquisados, tendo como objetivo propor uma formação continuada em serviço que oriente na/para prática do trabalho do professor em relação ao ensino da matemática nos anos iniciais do Ensino Fundamental em escolas do Campo. 
A estrutura organizativa do produto educacional compreende o referencial teórico como norteador da formação em serviço, um fluxograma das etapas formativas, a explicitação de cada etapa desenvolvida e as considerações finais. Nesta organização, explicitamos que o produto considera as demandas apresentadas pelos professores, bem como a organização dos estudos e busca materiais que subsidie os professores às novas práticas a partir da sugestão do professor. Todas as etapas foram realizadas de forma conjunta entre formador e professores no ambiente da sala de aula, desde a observação, planejamento, execução e avaliação da experiência formativa.

Para tanto, trazemos a orientação de que elaborar uma proposta de formação continuada em serviço dessa natureza seria preciso estabelecer relações de proximidade e confiança com os professores para que estes ao serem convidados a refletir sobre seus saberes e suas práticas docentes pudessem externar: a) desejo em ampliar e melhorar seu fazer docente; b) confiança na proposta formativa e no formador de forma a não sentir desconforto diante das situações de ensino reveladas no processo formativo; c) coragem para olhar e refletir sobre a ação docente; d) comprometimento com seu desenvolvimento profissional e com o desenvolvimento do aluno e d) reconhecimento de suas dificuldades/limitações no ensino de matemática.

Para atender a esses desafios, buscamos apoio no método da pesquisaação, por este permitir a identificação de possíveis contribuições da formação continuada no processo de construção/reconstrução dos saberes e práticas docentes dos professores, pois percebemos que esse método de pesquisa possibilitaria o envolvimento dos colaboradores da investigação na busca de conhecimento do objeto pesquisado. Nesses termos, Thiollent (2011), caracteriza a pesquisa-ação como um método que:

Consiste essencialmente em elucidar problemas sociais e técnicos, cientificamente relevantes, por intermédio de grupos em que encontram-se reunidos pesquisadores, membros da situação-problema e outros atores e parceiros interessados na resolução dos problemas levantados, ou pelo menos, no avanço a ser dado para que sejam formuladas adequadas respostas sociais, educacionais, técnicas e/ou políticas (THIOLLENT, 2011, p. 7).

Dessa forma, consideramos a pesquisa-ação o caminho que interligaria os conhecimentos adquiridos pelos professores na formação continuada com 
os possíveis conhecimentos a serem adquiridos por essa proposta formativa. Por entendermos a relevância da formação continuada na ampliação dos conhecimentos relacionados à prática docente, decidimos construir e desenvolver em caráter experimental essa proposta, cujas etapas formativas foram compreendidas em movimentos cíclicos de ação-reflexão-ação.

Com isso, evidenciarmos nessa proposta, a possibilidade de mobilização e reflexão dos saberes docentes envolvidos no contexto escolar. Utilizamos como embasamento teórico, referenciais que discutem a formação do professor na perspectiva da reflexão, dos saberes docentes, da profissão e da concepção, dentre eles destacamos: Alarcão (2011), Imbernón (2009), Tardif (2014), Freire (1987), Fiorentini (2005) e Nacarato (2013).

Sem dúvida a formação continuada em larga escala tem contribuído com o processo formativo dos professores dos anos iniciais das escolas do Campo, todavia, não o suficiente para provocar reflexões e alterações no fazer docente, pois os professores ao retornarem para sala de aula enfrentam dificuldades de natureza didática e de conteúdo, na maioria das vezes não contam com a colaboração da coordenação pedagógica da escola no sentido de ajudá-los a compreender a situação problema.

Conforme Alarcão (2011), para tornar-se professor reflexivo é necessário o desenvolvimento de uma consciência reflexiva na qual nos tornamos sujeitos criativos, críticos, inovadores etc. Dessa forma, esperamos que essa proposta formativa suscite nos professores dos anos iniciais das escolas do Campo o desejo de romper com o modelo reprodutivista desenvolvido há séculos nas escolas públicas brasileiras. Entretanto, "é necessário reconhecer as dificuldades pessoais e institucionais para pôr em ação, de uma forma sistemática a formação de natureza reflexiva" (ALARCÃO, 2011, p. 47).

$\mathrm{Na}$ orientação da construção dessa proposta, utilizamos como guia 0 material produzido pelos professores durante a investigação para que na condição de professores participantes dessa investigação percebessem como a formação continuada tem se relacionado com os fazeres pedagógicos e como eles reinventam suas práticas ao ensinar matemática na sala de aula a partir das orientações oferecidas pelo processo de formação continuada. 
Nessa perspectiva, a proposta foi tomando forma e à medida que organizávamos os materiais empíricos, as etapas formativas se definiam de acordo com a realidade emergida na sala de aula (ação) do processo formativo sobre a ação desenvolvida (reflexão) e da reorganização pós-reflexão (ação). Assim, a pesquisa foi se desenvolvendo com o intuito de ampliar os saberes pedagógicos desses professores, considerando que o lócus da aprendizagem é a escola e que essa deve funcionar como espaço de interação e partilha de saberes numa proposta reflexiva e colaborativa.

Por isso, é "preciso entender a escola como uma construção social, mediada pela interação dos diferentes atores sociais que nela vivem e com ela convivem" ALARCÃO (2011, p. 90). Ao passo que consideramos a escola um espaço em permanente construção, em função dos seus sujeitos serem dotados de conhecimentos que se renovam continuamente, e que a formação continuada em serviço visa contribuir com o desenvolvimento profissional dos professores.

Durante o desenvolvimento da formação em serviço, os professores ampliaram os conhecimentos acerca dos saberes docentes articulados às práticas pedagógicas promovidas pela reflexão entre seus pares sobre 0 desenvolvimento do ensino da matemática. Os professores se apropriaram de conhecimentos matemáticos necessários ao processo de ensino e de aprendizagem do Sistema de Numeração Decimal - SND, objeto matemático refletido à luz dos saberes advindo de suas vivências, das histórias de vida dos sujeitos que aprendem e das dificuldades contidas no cotidiano da escola.

Consideramos esse produto relevante ao contexto educacional podendo ser ampliado para todas as modalidades da educação básica e com essa expectativa, manifestamos a intenção de implementação dessa proposta junto à Secretaria Municipal de Educação (SEMED), com o objetivo de proporcionar aos coordenadores pedagógicos que atuam nas escolas do Campo nos anos iniciais, como possibilidade de desenvolver uma formação continuada em contexto de trabalho que contribua para ampliação dos saberes/conhecimentos envolvidos no desenvolvimento do ensino e da aprendizagem matemática a partir da demanda apresentada pelo professor em sala de aula. 


\section{FUNDAMENTAÇÃO TEÓRICA}

Na década de 1930, teve início no Brasil a formação de professores em pedagogia cuja finalidade era atender os alunos dos anos iniciais. Essa medida deu-se em decorrência da ampla inserção de alunos nas escolas públicas oriundos das camadas populares. Essa demanda passou a exigir mais professores e com isso o país se via diante de outra realidade e precisava de professores que não fossem leigos, mas com qualificação mínima em magistério.

Contudo, no final do século $X X$, teve início no país uma discussão sobre uma proposta de currículo cujo princípio centrava-se na problematização da formação dos sujeitos como possibilidade de crescimento humano. A partir desse pensamento, passou-se a perceber que seria preciso incluir no processo formativo dos professores elementos que tivessem a capacidade de contribuir com a formação social, política e humana.

A partir da aprovação da Lei n. 9.394/96, Lei de Diretrizes e Base da Educação - LDB, uma nova normatização começa a ser debatida e implementada no país, submetendo os cursos de formação de professores a uma reflexão sobre essa ótica, haja vista, que a LDB tinha como finalidade "atender os objetivos dos diferentes níveis e modalidades de ensino e as características de cada fase de desenvolvimento do educando".

Assim, criar condições e meios para atingir os objetivos da educação básica é a razão de ser dos profissionais da educação. Entretanto, a formação continuada de professores tem se consolidado na limitação de elementos políticos e teórico-metodológico, razão que tem impulsionado o ato de refletir/decidir sobre quais saberes são considerados necessários à escolarização e consequentemente à formação humana, levando em conta o espaço/meio em que vive o sujeito da aprendizagem.

Há tempos a educação brasileira vem sinalizando suas limitações, com isso diversas tentativas têm sido tomadas, prevendo a melhoria na qualidade do ensino, dentre elas, a oferta de Programas de formação continuada, por entender que a mudança na educação perpassa pelo trabalho do professor. 
Todavia, os problemas de ordem sociais, políticos e econômicos têm contribuído para o baixo desempenho do professor e consequentemente para o retardamento do desenvolvimento do país. Como Alarcão (2011),

O professor não é o único transmissor do saber e tem de aceitar situar-se nas suas novas circunstâncias que, por sinal, são bem mais exigentes. $O$ aluno também já não é mais o receptáculo a deixar-se rechear de conteúdo. O seu papel impõe-lhe exigências acrescidas. Ele tem de aprender a gerir e a relacionar informações para transformar no seu conhecimento e no seu saber. Também a escola tem de ser outra escola. A escola, como organização, tem de ser um sistema aberto, pensante e flexível. Sistema aberto sobre si mesmo, e aberto à comunidade em que se insere (ALARCÃO, 2011, p. 16).

Diante dessas afirmações compreendemos que é preciso melhorar a educação escolar, a fim de promover uma aprendizagem permanente de todos os responsáveis promovendo uma educação com qualidade, de forma a proporcionar a integração e conhecimento entre a sociedade. Nesse sentido, entendemos a educação como o caminho viável ao desempenho do homem em sociedade, com capacidade crítica, autêntico e verdadeiro, dotado de valores e comportamentos que os torne capaz de intervir na realidade para construir um mundo melhor.

Uma educação onde os professores interajam com os sujeitos que aprendem e ao mesmo tempo se tornem aprendentes das realidades envolta desses sujeitos. "Não há nada, contudo, de mais concreto e real do que os homens no mundo e com o mundo" (FREIRE, 1987, p. 127).

A escola do século XXI apresenta uma exigência com relação a mudanças no modelo de educação centrado no professor como transmissor do conhecimento, e provoca uma discussão nos cursos de formação inicial e continuada de professores de forma a acender o debate sobre o professor reflexivo se estendendo até o interior da escola. Nesse sentido (Alarcão, 2011, p. 44), define que a "noção de professor reflexivo deve se basear na consciência da capacidade de pensamento e reflexão que caracteriza o ser humano como criativo".

Assim sendo, a consciência do professor reflexivo se funda na consciência de sua identidade profissional, somente por meio dela o professor poderá viver permanentemente um processo de redescoberta do fazer diário 
num processo contínuo com seus pares. "O professor não pode agir isoladamente na sua escola, é neste local de trabalho, que ele, com os outros, seus colegas, constrói a profissionalidade docente" (ALARCÂO, 2011, p. 47).

Nesses termos, Alarcão (2011), nos orienta na compreensão de que o processo de reflexão exige um enorme esforço dos professores em sistematizar os conhecimentos a partir das ações que desenvolvem e das condições em que as desenvolvem, porém, nesse movimento reflexivo os professores apresentaram dificuldades para expressarem suas compreensões sobre capacidades reflexivas enquanto mecanismo de transformação da ação docente. Conforme (Alarcão, 2011, p. 63) é necessário que se compreenda que somente o "conhecimento que resulta da sua compreensão e interpretação permitirá a visão e a sabedoria necessária para mudar a qualidade do ensino e da educação".

Portanto, agindo dessa forma o professor torna-se reflexivo ao apresentar capacidade de pensar, refletir na ação e sobre a ação e nesse movimento de reflexão sobre sua prática constrói conhecimentos significativos à comunidade escolar. O chão da escola proporciona um ambiente formativo baseado na experiência individual e coletiva, na capacidade de escutar, observar e pensar, gerando conhecimento crítico, de tal forma que possibilite condições de reflexividade entre os sujeitos que a constituem. De acordo com Fiorentini (2005)

O professor é um profissional competente e responsável, que tem um papel fundamental a desempenhar no desenvolvimento curricular e em seu próprio desenvolvimento; de que ele detém conhecimento próprio e capacidade reflexiva e de ação quanto a sua prática e ao seu desenvolvimento profissional (FIORENTINI, 2005, p. 109).

Dessa forma, a competência profissional do professor reflexivo emerge da capacidade de encontrar maneiras criativas de exercer o conhecimento diante das condições de atuação, exercendo assim o poder de agente transformador numa sociedade marcada por dificuldades. Para Fiorentini (2005), os professores "não ensinam mecanicamente, de acordo com regras preestabelecidas, e que, dentre outras, a ação profissional docente deve estar fundamentada numa ação pedagógica crítico-reflexivo sobre o contexto em que se desenvolve". (FIORENTINI, 2005, p. 49).

BoEM, Joinville, v. 6, n. 11, p. 315-335, out 2018 
Em se tratando de ensino e de aprendizagem não só de matemática, mas de modo geral, o professor vive um momento de fortes cobranças. No entanto a realidade revela a imagem de um professor que não se sente devidamente preparado para lidar com a diversidade que ora se apresenta no contexto social, político e econômico, cabendo-lhe o desafio de que na condição de "profissional da educação deve constantemente aprender a aprender e refletir criticamente sobre sua prática". (FIORENTINI, 2005, p. 52).

É preciso observar para não cair na armadilha de se ater a um ensino simplista, superficial, desconexo com a realidade vivida e desejada pelos sujeitos que aprende. É necessário envolvimento do professor para que haja compreensão da complexidade que envolve o ensino, é preciso um processo formativo que incite o professor a tornar-se reflexivo sobre suas práticas pedagógicas e assim, possivelmente, promover alteração no seu fazer docente.

Nesse sentido, Schön (2000) defende que quanto mais o profissional experienciar ações, maior é a capacidade de usar as competências anteriormente adquiridas, "os atos de conhecer-na-ação e reflexão-na-ação entram em experiências de pensar e fazer que seja compartilhada por todos" (SCHÖN, 2000, p. 36). É refletindo sobre a ação desenvolvida que o professor recorrerá aos saberes acumulados pela sua experiência e aos saberes disciplinares para reorganizar sua ação docente e garantir a aprendizagem, haja vista, que as práticas pedagógicas são construídas por elementos que se interligam e se inter-relacionam.

Assim, os saberes dos professores são provenientes da formação inicial e continuada, da experiência de vida e das experiências desenvolvida no decorrer de suas práticas diárias, pois é no enfrentamento da realidade produzida pela sala de aula que se articula os conhecimentos necessários ao fazer docente. Para Imbernón (2006) a formação deve

Consistir em descobrir, organizar, fundamentar, revisar e construir a teoria. Se necessário, deve-se ajudar a remover o sentido pedagógico comum, recompor o equilíbrio entre os esquemas práticos predominantes e os esquemas teóricos que os sustentam (IMBERNÒN, 2006, p. 55).

Portanto, para que o professor que ensina matemática desenvolva essas competências a formação continuada deve ajudar a responder as lacunas que 
não foram preenchidas durante a formação inicial desses sujeitos. Dessa forma, as políticas de formação precisam reagir à essas exigências emergenciais, pois, no contexto atual somente assim a educação poderá cumprir sua finalidade em sentido amplo.

Nessa direção a proposta de formação considera que as práticas dos professores emergem da produção/mobilização dos saberes específicos que provém dessa mesma prática e não somente pelos modelos lineares que têm sido propostos há décadas, conforme Tardif (2014, p. 36) a "relação dos docentes com os saberes não se reduz a uma função de transmissão dos conhecimentos já constituídos". Mas, na relação entre os diversos saberes adquiridos na formação profissional e na atuação docente, é uma relação permanente de construção do conhecimento.

Nesse sentido, Tardif (2014, p. 20) diz que o saber do professor é temporal "significa dizer, que para ensinar supõe que se aprenda a ensinar, ou seja, aprenda a dominar progressivamente os saberes necessários a realização do trabalho docente". Assim sendo, a formação continuada assume a incumbência de promover a reflexão sobre o fazer dos professores com os professores no contexto da compreensão das necessidades educativas envolvidas no cotidiano da sala de aula.

\section{DETALHAMENTO}

O produto educacional originado da pesquisa do curso de Mestrado Profissional é fruto da relação direta entre meu processo de formação inicial, continuada, vivências e experiências adquiridas em contexto formativo, principalmente como professora formadora de professores dos anos iniciais das escolas do Campo.

Por um período de quatorze anos realizei acompanhamentos pedagógicos e desenvolvi formação continuada com professores de escolas do Campo, onde pude observar a pouca existência de estratégias metodológicas utilizadas pelos professores ao ensinarem matemática nos anos iniciais. Percebia que a formação continuada desenvolvida indicava várias estratégias de como planejar aulas para melhorar o ensino, objetivando a aprendizagem 
dos alunos, mas, na prática de sala de aula, os professores não as desenvolviam conforme as orientações. Mediante essas constatações o Mestrado Profissional trouxe a oportunidade de ampliar os estudos e fazer da prática formativa momentos de pesquisa aproximando a teoria da prática. Foi nesse movimento, que o produto educacional se constituiu enquanto proposta de formação continuada.

Com o propósito de deixar claro como o produto se constituiu, apresentamos abaixo o fluxograma e as etapas formativas que compõem a proposta de formação continuada em serviço. Todavia, informamos ao leitor e a quem interessar, que essas possibilidades de manifestação da organização do trabalho pedagógico têm a finalidade de possibilitar a reflexão sobre-a-ação e, nesse movimento, encontrar nas interações consigo e com os pares da escola meios de potencializar a aprendizagem gerida pelos professores em suas práticas diárias.

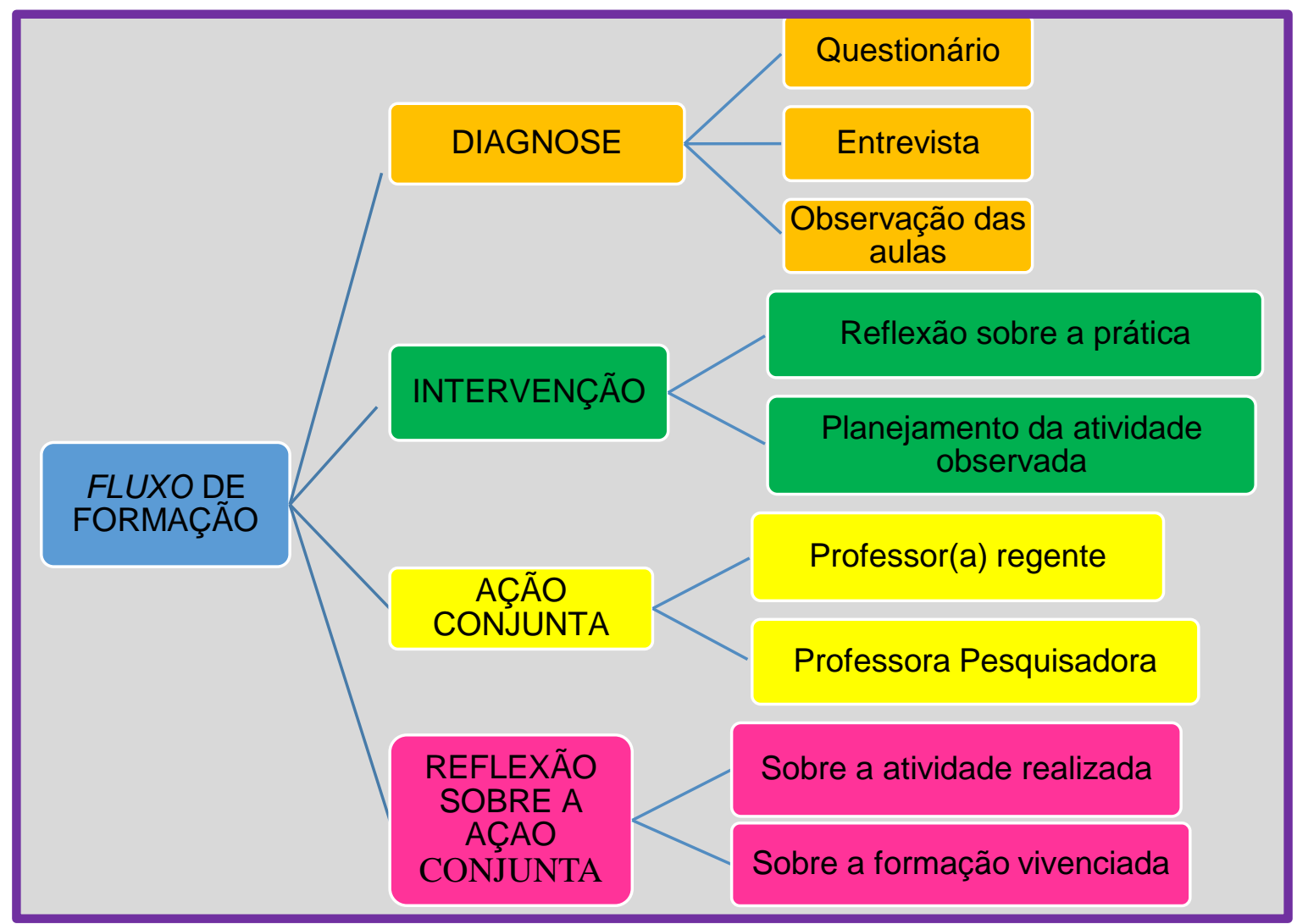

Fonte: Elaborado pela pesquisadora.

\subsection{Primeira etapa formativa - "DIAGNOSE"}


De acordo com o fluxograma essa etapa formativa se constituiu a partir de três fases: (a) levantamento dos dados dos sujeitos participantes da investigação (b) concepção de práticas pedagógicas e (c) observação da ação docente. Por um período de seis meses estabelecemos os contatos iniciais com os professores, sendo que nos encontrávamos a cada quinze dias com dia e horário previamente marcados nas escolas onde cada um trabalhava. Essa atitude foi em decorrência da localização das escolas e do princípio de não retirar os professores da sala de aula.

Nessa etapa consideramos o questionário um recurso favorável ao levantamento das informações iniciais, por esse apresentar uma estrutura com organização de questões intencionadas e flexíveis, de forma a permitir que os professores participantes expressassem seu pensamento de acordo com a compreensão que tem sobre as questões apresentadas. Segundo Thiollent (2011, p. 75) "na pesquisa-ação o questionário não é suficiente em si mesmo". Dessa forma, entendemos que, além do questionário, precisaríamos de outros instrumentos de coleta para melhor captar as informações oriundas do campo da pesquisa, dentre elas utilizamos: entrevista; observação; gravações; e, registros escritos.

Na segunda parte da diagnose, utilizamos a entrevista semiestruturada por se configurar como um instrumento de coleta de dados que mobiliza os sujeitos da investigação a participarem ativamente. Para tanto, elaboramos um roteiro de entrevista organizada a partir de quatro questões relacionadas às práticas pedagógicas dos participantes. Para não comprometer 0 desenvolvimento das atividades docentes as entrevistas foram realizadas nas escolas de forma individual nos intervalos entre as aulas.

Conforme esperado, as entrevistas trouxeram detalhes que só a oralidade permite, ou seja, outros elementos complementares que se agregaram nas informações contidas nas respostas expressas nos questionários permitiram ao pesquisador, maior acesso ao contexto investigado. Assim, compreendemos que a entrevista foi uma ferramenta fundamental e uma vez agregada ao trabalho investigativo, proporcionou ao pesquisador reflexões mais abrangentes em relação ao fenômeno investigado. 
A última fase da diagnose consistiu na observação das aulas. Nessa fase, acompanhamos cada um dos cinco professores em sala de aula, com objetivo de levantar informações sobre o desenvolvimento do trabalho didáticopedagógico, para, em momento posterior, refletirmos juntos sobre a ação e as impressões observadas no processo de ensinar matemática nos anos iniciais em escolas do Campo.

Para o desenvolvimento desta etapa, o primeiro passo realizado foi construir um cronograma com a participação e anuência dos professores e dos gestores das escolas, com vistas a organizar datas e horários em que aconteceriam as observações de forma a garantir a participação de todos os envolvidos na pesquisa sem comprometer a qualidade das aulas.

Para não causarmos desconforto aos alunos, adotamos como estratégia de aproximação visitar cada uma das turmas nas escolas onde era desenvolvida a pesquisa. Em cada sala, utilizando linguagem acessível à compreensão dos alunos, procuramos explicitar os motivos pelos quais estaríamos utilizando instrumentos para coletar dados em sala de aula. Esse procedimento foi de suma importância para a pesquisa, pois permitiu familiarização com os alunos, contribuindo para que a observação ocorresse com naturalidade.

Após esse processo de familiarização, iniciamos a observação em todas as salas de aula em dias alternados. Em cada uma delas, solicitávamos ao professor o planejamento da aula a ser realizada, para que pudéssemos verificar qual seria a estrutura que organizava o ensino e a aprendizagem de determinado conteúdo matemático. A partir do momento que se iniciava a aula, passávamos a utilizar, além da filmagem, registros por escrito, pois caso ocorresse algum imprevisto com a câmera, as observações não ficariam comprometidas.

A partir das informações apresentadas nos planejamentos, conforme amostragem abaixo, identificamos que os planejamentos estavam organizados em forma de roteiro e/ou listagem de conteúdo a serem desenvolvidos, não havia detalhamento das etapas de desenvolvimento. Também foi possível perceber que somente um planejamento apresentava os objetivos e indícios 
metodológicos, porém os demais não continham os elementos estruturantes e condicionantes de um planejamento.

\section{Plano de aula desenvolvido pelos professores durante a etapa de observação.}

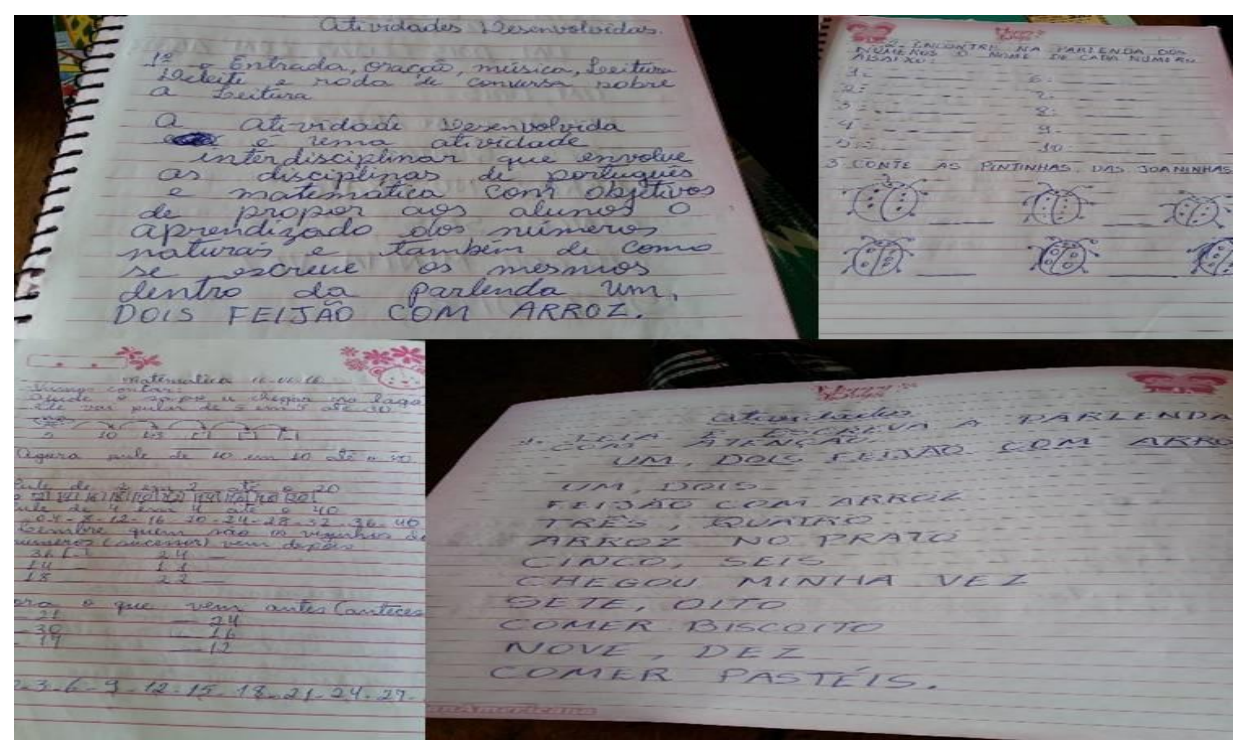

Fonte: pesquisadora, 2017.

Contudo, identificamos que, durante o desenvolvimento da aula ministrada pelos professores, a maioria dos alunos não apresentava familiaridade com o conteúdo matemático, impedindo-os de avançarem nas aprendizagens.

Percebemos que ao apresentarem os conteúdos aos alunos, os professores não explicitavam os elementos constitutivos daquela aula, por exemplo, o conteúdo da aula, o que os alunos deveriam aprender, a duração da aula, por que a sala estava organizada de outra forma e como seria a avaliação da aula.

Ao concluirmos as observações das aulas de cada professor, fizemos um mapeamento de todos os elementos registrados com a finalidade de propor reflexões sobre a própria prática. Com esse propósito, retornamos às escolas, para dar continuidade na segunda etapa de formação, agora apoiada nas informações resultantes da diagnose, principalmente, do processo de observação, para que juntos pudéssemos refletir sobre as estratégias de ensino por eles desenvolvidas. 


\subsection{Segunda etapa formativa - "REFLEXÃO SOBRE A}

AÇÃO" Essa etapa compreendeu três fases de desenvolvimento, com foco no processo de reflexão da ação desenvolvida, de forma a promover uma ação colaborativa com os sujeitos cujo propósito seria o de perceberem o uso e as contribuições das ferramentas utilizadas nas práticas pedagógicas para aquisição da aprendizagem, e como essas poderiam ser refletidas e planejadas de forma a atingir o desafio de ensinar matemática nos anos iniciais.

A primeira fase dessa segunda etapa formativa consistiu no processo de reflexão sobre as aulas observadas à luz das observações e do olhar da pesquisadora, que organizou as unidades que emergiram da observação. Durante essa etapa, os professores foram convidados, individualmente, a assistirem as aulas filmadas e refletirem junto com a pesquisadora acerca das situações de ensino observadas na aula de matemática. Esse processo foi fundamental para evolução dos saberes presentes no ato de ensinar.

A segunda fase consistiu na realização de estudos teóricos sobre professor reflexivo e saberes docentes, fundamentados em Alarcão (2011) e Tardif (2014), com a intenção de mobilizá-los acerca da necessidade de uma formação em contexto escolar, baseada na experiência e no diálogo de forma a vê-la como possibilidade de tornarem-se professores reflexivos da própria prática.

A terceira fase consistiu no planejamento da ação pós-reflexão. Nessa etapa considerou-se o nível de conhecimento dos professores e os entraves presentes nas práticas ao ensinarem matemática. Para tanto, no desenvolvimento do planejamento foram levantadas situações de atividades práticas, envolvendo o uso de materiais manipulativos, (dados, baralho, ábaco, cartela de números, fichas coloridas, palitos de picolé, grãos, tampas de garrafas, caderno e lápis) como possibilidades de ampliação da compreensão sobre o objeto de estudo.

Todas as fases dessa etapa foram realizadas, individualmente, por considerarmos que a reflexão coletiva poderia, inicialmente, causar desconforto e constrangimento aos professores em função da exposição das situações de ensino identificadas a partir das observações em seus contextos de trabalho. 
Durante as reflexões sobre as práticas observadas nas aulas, os professores foram percebendo que se tivessem dado mais atenção aos planejamentos, provavelmente os resultados poderiam ter sido diferentes.

A ausência desse movimento reflexivo no fazer dos professores é o que Imbernón (2011, p. 41) chama a atenção, afinal para ele o processo de "formação dos professores deve garantir conhecimentos, habilidades e atitudes para desenvolver profissionais reflexivos ou investigadores".

No processo de reflexão sobre a ação, indagamos os professores sobre alguns aspectos relacionados à pratica didático-pedagógica, os quais se mostraram surpresos, por exemplo: Por que não informou aos alunos qual era o objetivo da aula? Por que realizou as leituras deleites em pé, de frente para os alunos em vez de fazer a roda de leitura para envolver todos os alunos? Por que não construiu regras de convivências com os alunos, com vistas à melhoria da indisciplina? Por que não relacionou os conteúdos ensinados, anteriormente, nas aulas de matemática, com esse conteúdo trabalhado?

Questões dessa natureza foram usadas como apoio para reflexão sobre as práticas pedagógicas desenvolvidas pelos professores, considerando, que, durante as aulas, identificamos nas práticas de todos os professores um distanciamento em relação ao ensino de Matemática. Essa observação se constatou nas falas dos professores ao afirmarem que ensinam matemática aos alunos uma ou duas vezes por semana.

De acordo com Nacarato (2013), é preciso ressignificar os saberes que advém da formação e articulá-los aos saberes do conteúdo de sala de aula, segundo a autora "é a partir da problematização da prática que o professor passa a refletir e produzir significados para os acontecimentos que vivencia" (NACARATO, 2013, p. 200).

Ao concluirmos as reflexões provocadas pelas observações das aulas, convidamos os professores a fazerem outro planejamento em colaboração com a pesquisadora, envolvendo o mesmo conteúdo, porém, definindo cada etapa de desenvolvimento da aula. Os professores não apresentaram resistência e aceitaram a proposta. No entanto, antes de iniciarem o planejamento foram convidados a fazerem um estudo do texto "A formação do professor reflexivo" Alarcão (2011). 
O texto proporcionou aos professores melhor entendimento sobre o que significava refletir sobre a própria prática, sobre a ação coletiva, sobre a capacidade de pensamento e reflexão, sobre a pesquisa, enquanto instrumento de conhecimento, sobre a relevância do diálogo no processo formativo, sobre a contribuição do formador de professor à sua prática docente, entre outros.

A partir das reflexões, retomamos e estruturamos as etapas do planejamento, definindo os objetivos de ensino; os objetivos de aprendizagem; conteúdo matemático, metodologia, materiais de apoio didático e avaliação. Ao definirmos as etapas, nos debruçamos sobre as literaturas existentes na escola em busca de leituras que se articulassem com a faixa etária e com o conteúdo de ensino proposto.

Após selecionarmos todo material didático disponível na escola, passamos a organizar cada etapa do planejamento, considerando os conhecimentos matemáticos de cada aluno e organizando-os em duplas as quais chamamos de produtivas definidas pelo nível de conhecimento de cada aluno, um processo de ajuda mútua. A cada elemento constitutivo do planejamento os professores refletiam sobre a necessidade que eles tinham em conhecer mais sobre o objeto de ensino, o olhar do outro sobre o que eles estão fazendo, um trabalho coletivo aonde cada um venha aprender com a experiência do outro, com reflexões que orientem para melhoria da ação docente.

\subsection{Terceira etapa formativa "AÇÃO CONJUNTA"}

Nessa etapa aconteceu o desenvolvimento do planejamento, a partir das ações refletidas pelo pesquisador e pelos professores em decorrência das observações das ações das práticas observadas em sala de aula. Nesta terceira etapa eu - pesquisadora - numa ação conjunta com os professores fomos para sala de aula e colocamos em prática o que havíamos planejado, com vistas à uma nova reflexão, ou seja, reflexão da reflexão sobre a ação.

Da forma como planejado, chegamos mais cedo a escola e organizamos a sala de aula para recebermos os alunos. Essa organização foi um diferencial no planejamento, pois como havíamos decidido que a atividade de matemática a ser desenvolvida naquela aula seria em dupla. Decidimos que a leitura deleite seria compartilhada numa roda de leitura, então, organizamos o espaço com 
tapetes e almofadas para que as crianças ficassem bem à vontade, observando que todos os materiais utilizados na aula eram de propriedade das escolas, o que nos convidava à reflexão de que possivelmente a ausência na prática de planejar o passo a passo de uma aula, poderia contribuir para não exploração do material de apoio didático que as escolas dispõem.

A chegada dos alunos na sala de aula foi impactante, todos olharam para a organização da sala e perguntaram por que estava daquela forma. Ao se depararem com o espaço da leitura ficaram eufóricos, alguns logo sentaram sobre o tapete, outros apenas admiravam.

Contudo, não foi objetivo dessa pesquisa apontar se os professores desenvolvem ou já desenvolveram práticas semelhantes, nem tampouco afirmar que o planejado é algo novo, excepcional, diminuindo o que eles já fazem. A intenção foi de provocá-los a refletir sobre sua ação docente, pois conforme Tardif (2014), na maioria das vezes as ações dos professores assumem consequências que não foram previstas e que às vezes não conseguem explicar sua existência.

\subsection{Quarta etapa formativa "REFLEXÃO SOBRE A AÇ̃̃O CONJUNTA"}

Essa última etapa se constituiu em um processo de reflexão sobre as experiências decorrentes da investigação. Esse momento foi de muito aprendizado para todos os envolvidos, foi o momento que reunimos os cinco participantes para avaliarmos as etapas de desenvolvimento dessa pesquisa. A etapa configurou-se como a última de um movimento "cíclico", ficou marcada em função da tomada de consciência dos professores em relação ao processo de formação reflexiva desenvolvida em contexto escolar.

Nesse momento cada professor socializou as experiências que teve com a formação em contexto escolar, as contribuições trazidas por cada etapa desenvolvida ao fazer docente, a importância do planejamento sistematizado para o desenvolvimento da aula, as abordagens feitas pela pesquisadora, às intervenções na prática docente, os saberes dos alunos como ponto de partida para a ação, a participação direta do coordenador pedagógico no processo de 
reflexão do/no fazer docente, enfim, o momento foi de avaliação e de proposições.

De acordo com Alarcão (2011), a formação continuada precisa estar situada no coletivo do contexto escolar para que o paradigma de professor reflexivo possa ser mais valorizado. Entretanto os professores perceberam que um processo formativo como esse que se observa, investiga, problematiza e reflete sobre o que faz poderá proporcionar melhores resultados no redirecionamento dos saberes docente.

Nessa perspectiva, os sujeitos da investigação avaliaram que o processo de intervenção realizado durante as etapas formativas foi um exemplo da ação colaborativa, onde o envolvimento conjunto possibilitou a reflexão sobre as práticas didático-pedagógicas, sobre os conteúdos matemáticos, e, sobre a estrutura curricular.

\section{CONSIDERAÇÕES}

Chegar até aqui foi mais que um aprendizado, a cada etapa vivenciada nesta investigação me projetava a rever meus conceitos de professora formadora de professores, minhas certezas e incertezas. Cada etapa me proporcionou novas reflexões dos quão complexos são os caminhos entre o ensinar e o aprender. Ao me propor investigar sobre os significados de uma experiência formativa por meio de uma proposta de formação, em serviço, me dediquei a observar, escutar, compreender e aprender com os sujeitos da investigação.

Conforme descrito nas etapas formativas, o objetivo central desse produto consistiu na organização de uma proposta de formação, em serviço, que mediada pelos referenciais teóricos e pelos saberes dos professores, orientassem a organização do trabalho pedagógico como contributo da formação continuada a partir da observação, reflexão, intervenção e reorientação das práticas de ensino da matemática desenvolvidas em sala de aula pelos professores dos anos iniciais de escolas do Campo. 
Com vistas a atender as demandas apresentadas no objetivo da proposta, compreendemos que a formação desenvolvida em contexto de trabalho promoveu maior entendimento sobre o ato de ensinar e as implicações nele contido, pois a pesquisa proporcionou mobilidade organizativa dos saberes dos professores e da relação com a prática pedagógica desenvolvida durante as aulas.

Nesse sentido, destinamos esse produto aos coordenadores pedagógicos das escolas do Campo, que em uma de suas muitas atribuições educacionais compete à organização do trabalho pedagógico e também a formação continuada dos docentes. Dessa forma, suponhamos que ao desenvolverem essa proposta de formação em serviço, estarão oportunizando aos docentes e a si mesmo, a possibilidade de identificar os fatores condicionantes do ensino, atrelados aos saberes dos professores, e nessa relação conjunta, promoverão alteração no ensino e na aprendizagem podendo constituir um grupo de pesquisadores da própria prática mediados pela ação colaborativa dentro da escola.

\section{REFERÊNCIAS}

ALARCÃO, Isabel. Professores reflexivos em uma escola reflexiva / Isabel Alarcão. - 8ª ed.- São Paulo: Cortez, 2011.

BRASIL. Lei de Diretrizes e Bases da Educação Nacional (LDB): Lei no 9394, 20 de dezembro de 1996, Brasília: Senado Federal, 1997.

FIORENTINI, Dário. Cultura, formação e desenvolvimento profissional de professores que ensinam matemática: investigando e teorizando a partir da prática / Dário Fiorentini e Adair Mendes Nacarato (organizadores). Campinas, SP: Musa Editora, 2005.

FREIRE, Paulo. Pedagogia do oprimido. 38a․ ed. Rio de Janeiro: Paz e Terra 1987.

IMBERNÓN, Francisco. Formação docente e profissional: formar-se para a mudança e a incerteza. 6ª . ed. São Paulo: Cortez, 2006.

Formação permanente do professorado: novas tendências; tradução de Sandra Trabuco Valenzuela. São Paulo: Cortez, 2009.

NACARATO, Adair Mendes; PAIVA, Maria Auxiliadora Vilela (Org). A formação do professor que ensina Matemática: perspectivas e pesquisas. 3ª . ed. Belo Horizonte: Autêntica, 2013. 
http://dx.doi.org/10.5965/2357724X06112018315

TARDIF, Maurice. Saberes docentes e formação profissional. $17^{\underline{a}}$ ed. Petrópolis, RJ: Vozes, 2014.

THIOLLENT, Michel. Metodologia da pesquisa-ação - 18a․ ed. São Paulo: Cortez, 2011. 